\title{
Not the Last Word
}

\section{Not By Bread Alone: Shortcomings of the Pay-For-Performance Approach}

\author{
Joseph Bernstein MD
}

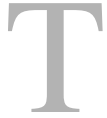

hese days, surgeons are fixing clavicle fractures more frequently. It is fair to wonder why. After all, it was only 1994 when Jupiter and Mullaji [11] declared that "internal fixation of the clavicle is rarely necessary." One explanation is that we may simply have learned that fixation is, in fact, the superior approach [4]. Another explanation might be cognitive or social biases. For example, our experience with fibulas

The author certifies that he, or any member of his immediate family, has no funding or commercial associations (eg, consultancies, stock ownership, equity interest, patent/ licensing arrangements, etc) that might pose a conflict of interest in connection with the submitted article.

All ICMJE Conflict of Interest Forms for authors and Clinical Orthopaedics and Related Research ${ }^{\circledR}$ editors and board members are on file with the publication and can be viewed on request.

The opinions expressed are those of the writers, and do not reflect the opinion or policy of Clinical Orthopaedics and Related Research $^{\circledR}$ or the Association of Bone and Joint Surgeons ${ }^{\circledR}$.

J. Bernstein MD ( $\square)$

Department of Orthopaedic Surgery,

University of Pennsylvania,

424 Stemmler Hall, Philadelphia,

PA 19104, USA

e-mail: orthodoc@uphs.upenn.edu and femurs may produce a false belief that broken bones are happier with hardware. Surgeons may also have noticed that patients are more grateful when a bone heals after an operation.

The one explanation that almost certainly is incorrect is that surgeons are performing more operations to make more money. Granted, the fees for operative fixation are higher than those for nonoperative treatment but not by much. (For Medicare, the fee is approximately USD 350 more.) Besides, surgery takes time and effort, and surgery is riskier; as the name implies, the subclavian vessels are, indeed, right beneath the clavicle.

While we should be open to the idea that subtle [15] or large inducements can be effective motivators, the claim that surgeons will change their approach to patient care in response to an overt, yet small financial inducement is unlikely to be true.

Despite that, financial inducements that are both overt and small underlie the so-called "pay-for-performance" approach. According to a Leapfrog report [3], pay-for-performance programs offer more money for "performance of quality and efficiency measures so that desired outcomes occur through changed behavior." The report further notes that typical pay- for-performance bonuses are about $10 \%$ of the total payment [3].

The first criticism of pay-for-performance programs is that they are not likely to work - the payments are too overt and too small. The more fundamental complaint is that if pay-forperformance programs were to successfully change behavior, they would do so only by distracting doctors from the care of patients. In point of fact, the program would be distracting even if it failed to change behavior.

You may recall the last time Medicare tried to change behavior with small and overt payments. In the 1990's, physicians were chided that their "medical records did not adequately document their involvement in services" [17]. This admonishment led to a system of billing that explicitly linked the payment for services to the documentation of services. The ostensible goal of this program was to produce lower bills. Instead, from 2001 to 2010, the average work effort charged per single clinical encounter rose by $31 \%$ [9]. The best explanation for this phenomenon is that physicians mastered the arcana of coding, and learned to write notes that wring out the last unit of billable work. This not only undermined the aim of the program, it distracted physicians from patient care. Every moment that an orthopaedic 


\section{Not the Last Word}

surgeon looks down at a data-entry screen and not up a patient, every time an Academy session like "ICL-153: The Top 10 Coding Errors Made by Practicing Orthopaedic Surgeons" is chosen over a real orthopaedic course, the care of patients is subordinated to more mundane issues. A pay-for-performance approach would likely become just as distracting and just as ineffective.

For example, if we adopted a pay-forperformance approach, an orthopaedic surgeon might potentially receive a small bonus every time a patient avoids a deep vein thrombosis after joint replacement. If nothing else, rewarding a low rate of deep vein thromboses without considering the clinical context is a poor policy from a medical point of view. (It is an incentive to anticoagulate to the point of hemorrhage, and it is an inducement to ignore deep vein thromboses when they do occur.) Worse, such a program creates the wrong mindset. Once you assert that earning an additional 67 cents is a valid reason for avoiding a deep vein thrombosis, you open the door to the notion that a surgeon can put deep vein thrombosis completely out of mind, as long as his cavalier attitude frees him to do other things earning at least 68 cents more. However reckless this attitude may be, it is "cost-effective."

What I have suggested will happen with pay-for-performance incentives in the realm of deep vein thrombosis outlines the four probable results in every realm: (1) the quality metrics will be attained; (2) the bonuses will be paid; (3) patient care will truly be no better; and (4) doctors will be distracted.

Society should not want its physicians preoccupied by bonus payments. Paying more for good performance is a wonderful concept, if truly good performance can be identified, and if the payment program can be implemented without distraction. Pay-for-performance does not meet those ideals.

This criticism is not based on a longing for the good old days, when money was never a concern. Such days never existed. It is clear that healthcare represents $18 \%$ of our gross domestic product, and that share is growing. It is clear that financial considerations must enter the practice of orthopaedic surgery. But it should be equally clear that orthopaedic surgeons are not pure economic actors either. As such, the best way to get surgeons to do the right thing is to appeal to their professionalism, not their wallets. Pay-for-performance, as currently construed, is a well-intentioned step in the wrong direction.

\section{Kevin J. Bozic MD, MBA}

Department of Orthopaedic Surgery, University of California, San Francisco, CA

\section{David S. Jevsevar MD, MBA}

Orthopaedic Surgeon, Zion Orthopaedics and Sports Medicine, St. George, UT
Dr. Bernstein presents an interesting and important perspective on the limitations of pay-for-performance programs. We agree that many pay-forperformance programs, as currently designed, lack sufficient financial incentives to influence practice [12], and may incentivize inappropriate "gaming" of the system. We also agree that a minority of healthcare providers make patient care decisions purely based on financial incentives. However, we strongly advocate for and support a payment system that rewards value over volume and intensity of services. The current fee-for-service payment system places the emphasis on "care" rather than health, with little or no incentive for preventative care. This system has done little to constrain unsustainable growth in healthcare spending, and has resulted in wide variability in practice patterns [16], with low rates of adherence to evidence-based best practices [10].

An ideal payment system would incentivize providers to work collaboratively, optimizing the health of their patients while making efficient use of scarce healthcare resources. In orthopaedics, this could mean addressing modifiable risk factors prior to undertaking elective surgical interventions. Under the current fee-for-service payment system, orthopaedic surgeons frequently operate on patients with modifiable risk factors, such as obesity, smoking, or poorly controlled 
diabetes, despite the fact that each of these risk factors has been shown to be associated with a higher rate of surgical complications and greater resource utilization $[8,14,18]$. In a value-based payment system where provider payment is tied to both outcomes and cost of care, orthopaedic surgeons would be incentivized to work with their primary care colleagues to encourage patients to lose weight, quit smoking, and optimize their blood glucose prior to undergoing elective orthopaedic procedures.

Wennberg [16] and others have repeatedly shown wide geographic variability in the utilization of invasive and resource-intensive healthcare services, such as spine surgery for low back pain. Given the lack of clearly defined indications for many surgical procedures, and the strong financial incentives for surgical versus nonsurgical care, with no regard for value (as defined by improvement in health outcome per dollar spent), it is no surprise that some policy experts estimate that $17 \%$ to $22 \%$ of surgical procedures are deemed unnecessary $[1$, $6]$.

Orthopaedic surgeons have an important role to play to developing and implementing a more value-conscious payment system. First, we need to be actively involved in defining the appropriate indications for diagnostic (MRI) and therapeutic (surgery) musculoskeletal interventions. This includes implementing shared medical decision making programs which allow providers to incorporate patient preferences and values into their treatment recommendations. Second, we need to develop evidence-based performance measures, including both process (administration of antibiotics) and outcome (surgical complication) measures. Third, we need to implement systems that allow us to measure outcomes and costs in real time, and incorporate this information into our medical decision-making. Finally, we need to work collaboratively with patients, other providers (including hospitals), payors, and policy-makers to ensure that value-based payment systems achieve their goal of improving health while conserving scarce healthcare resources.

Physicians in general and orthopaedic surgeons in particular, have both an opportunity and obligation to develop solutions for the many challenges that our healthcare system currently faces. Taken alone, physician professionalism has not demonstrated the ability to improve quality or reduce the cost of healthcare in the United States. If designed and implemented properly, valuebased payment systems such as payfor-performance could play a critical role in helping us achieve those elusive goals.

\section{David J. Shulkin MD}

President, Morristown Medical Center, Morristown, NJ

Dr. Bernstein and I both arrived at the University of Pennsylvania in 1990, each to pursue our postgraduate studies. We never met, maybe because he spent more time in the operating rooms of the Hospital of the University of Pennsylvania, and I spent more time on the other side of Spruce Street with my business school colleagues at Wharton. No wonder our perspectives on healthcare differ.

To argue, as Dr. Bernstein does, that financial incentives are not strong influencers of physician behavior, ignores the body of literature that suggests that they surely do [5]. Yet, I find myself agreeing with Dr. Bernstein that many of the systems that provide financial rewards to doctors, the so called pay-for-performance systems, are not achieving their goals. Many fail due to the complexity of measurement and data collection efforts, as well as the payers' unwillingness to provide meaningful incentives.

One of my first lessons at Wharton was that effective incentives must represent at least $18 \%$ of the physicians' income level [7]. Few programs reach this level of financial reward, and the limited results we often see should be of no surprise. Dr. Bernstein is correct that the requirements to 
participate in pay-for-performance systems often amount to unfunded mandates, with the administrative complexity of conforming to the programs often costing more than the benefits achieved. Administrative burdens placed upon healthcare providers have made it increasingly difficult for providers to focus on improving clinical practice [13].

Dr. Bernstein is also correct in pointing out the unintended consequences of programs that focus on specific clinical measures. For example, it is well known that reporting efforts focused on the rapid administration of antibiotics have potentially led to an increase in inappropriate drug prescribing [2]. As Dr. Bernstein points out, when achieving a particular clinical endpoint becomes the primary goal (efforts to reduce deep vein thromboses, for example) other important clinical objectives may be overlooked, perhaps causing - in aggregate - more harm than good. The correct selection of the targets for pay-for-performance systems needs to be evaluated rigorously, with thoughtful field-testing of each measure prior to integrated specific changes of this kind into our payment systems.

The large variation in clinical practices and documented deviations from accepted practices is not something that we, as professionals, can walk away from [10]. We must use both science and economics to weed out those practices that are not effective, and reward those that are. If we allow patients and payers to view the results of both cost and outcomes, then we can integrate these into effective payment systems that will make quality healthcare more sustainable. The accountable care organization movement, now being led by many provider groups, is a positive development in this regard.

We all agree there are problems when our clinical and economic systems come together. But acknowledging the flaw in pay-for-performance programs should not cause us to abandon them. We must find effective value-based payment systems, and we should continue to consider pay-for-performance approaches, along with any others that marry reasonable approaches to reimbursement to good clinical performance. The first step towards this will be for providers to take ownership and accountability for these systems.

\section{References}

1. Al-Khatib SM, Hellkamp A, Curtis J, Mark D, Peterson E, Sanders GD, Heidenreich PA, Hernandez AF, Curtis LH, Hammill S. Non-evidencebased ICD implantations in the United States. JAMA. 2011;305:43-49.

2. Baker DW, Qaseem A. Evidencebased performance measures: preventing unintended consequences of quality measurement. Ann Int Med. 2011;1555: 638-640.

3. Baker G. Pay for performance incentive programs in healthcare: Market dynamics and business process. Available at: http://www.leapfroggroup. org/media/file/Leapfrog-Pay_for_ Performance_Briefing.pdf. Accessed October 28, 2013.

4. Canadian Orthopaedic Trauma Society. Nonoperative treatment compared with plate fixation of displaced midshaft clavicular fractures. A multicenter, randomized clinical trial. J Bone Joint Surg. 2007;89:1-10.

5. Eisenberg JM. Doctors' Decisions and the Cost of Medical Care: The Reasons for Doctors' Practice Patterns and Ways to Change Them. Chicago, IL: Health Administration Press; 1986:1-190.

6. Epstein NE, Hood DC. "Unnecessary" spinal surgery: A prospective 1-year study of one surgeon's experience. Surg Neurol Int. 2011;2:83.

7. Hillman AL. Health maintenance organizations, financial incentives, and physicians' judgments. Ann Int Med. 1990;112:891-893.

8. Jamsen E, Nevalainen P, Eskelinen A, Huotari K, Kalliovalkama J, Moilanen T. Obesity, diabetes, and preoperative hyperglycemia as predictors of periprosthetic joint infection: a single-center analysis of 7181 primary hip and knee replacements for osteoarthritis. J Bone Joint Surg Am. 2012;94:e101.

9. Levinson DR. Coding trends of Medicare evaluation and management services. Available at: https://oig.hhs. 
gov/oei/reports/oei-04-10-00180.pdf. Accessed October 28, 2013.

10. McGlynn EA, Asch SM, Adams J, Keesey J, Hicks J, DeCristofaro A, Kerr EA. The quality of health care delivered to adults in the United States. N Engl J Med. 2003;348:2635-2645.

11. Mullaji AB, Jupiter JB. Low-contact dynamic compression plating of the clavicle. Injury. 1994;25:41-45.

12. Rosenthal MB. Beyond pay for performance-emerging models of provider-payment reform. $N$ Engl J Med. 2008;359:1197-1200.
13. Shulkin DJ, Hillman AL, Cooper WM. Reasons for increasing administrative costs in hospitals. Ann Int Med. 1993;119:74-78.

14. Singh JA. Smoking and outcomes after knee and hip arthroplasty: a systematic review. J Rheumatol. 2011;38:1824-1834.

15. Thaler RH, Sunstein CR. Nudge: Improving Decisions About Health, Wealth, and Happiness. New York, New York: Penguin Books; 2008:1-320.

16. The Dartmouth Institute for Health Policy \& Clinical Practice. The
Dartmouth atlas of health care. Available at: http://www.dartmouthatlas. org/. Accessed January 10, 2013.

17. United States General Accounting Office. Report to the chairman subcommittee on health, committee on ways and means, house of representatives. Available at: http://www.gao. gov/archive/1998/he98174.pdf. Accessed October 28, 2013.

18. Vasarhelyi EM, MacDonald SJ. The influence of obesity on total joint arthroplasty. J Bone Joint Sur Br. 2012;94:100-102. 